\title{
Thermophysics Analysis of Office Buildings with a Temperature-Humidity Coupling Strategy Under Hot-Arid Climatic Conditions
}

\author{
Mohammed Bensafi ${ }^{1} \cdot$ Houari Ameur $^{2}$. Noureddine Kaid ${ }^{1,2}$. \\ Siamak Hoseinzadeh ${ }^{3}$ (D) Saim Memon ${ }^{4}$. Davide Astiaso Garcia ${ }^{3}$
}

Received: 8 February 2021 / Accepted: 27 April 2021 / Published online: 1 June 2021

(c) The Author(s) 2021

\begin{abstract}
This study investigates the determining parameters of thermal comfort of office in an arid hot-arid environment of Bechar, located in the northwestern region of Algeria, in which the vertical walls of the room and the roof are subjected to solar irradiations and the floor is considered to be adiabatic. The solar flux is calculated by the ASHRAE (American Society of Heating, Refrigerating and Air-Conditioning Engineers) method. The predicted results are validated against the experimental results of the meteorological station of the ENERGARID research laboratory at the University of Bechar (Algeria). The characteristics of the ambient air flow are performed by using the computational fluid dynamics (CFD) software (Fluent). The flow fields, thermal fields, and humidity are investigated. An elaborated computer program (with Delphi language) is utilized to evaluate the temperature-humidity coupling as the most essential factors of the thermal comfort. A significant impact of dynamic temperatures and humidity on thermal comfort has been observed, especially in this hot-arid environment. Besides, a considerable effect of the flow velocity has been remarked. From the obtained results and to provide the best thermal comfort in such arid regions, the range of air velocity inside the building is recommended to be between $0.2 \mathrm{~m} \cdot \mathrm{s}^{-1}$ and $0.3 \mathrm{~m} \cdot \mathrm{s}^{-1}$.
\end{abstract}

Keywords Arid region · Building · Solar flux $\cdot$ Thermal comfort $\cdot$ Temperaturehumidity coupling

\section{List of symbols}

$\begin{array}{ll}C_{\mathrm{p}} & \text { Specific hat capacity }\left(\mathrm{J} \cdot \mathrm{kg}^{-1} \cdot \mathrm{K}\right) \\ k & \text { Thermal conductivity }\left(\mathrm{W} \cdot \mathrm{m}^{-1} \cdot \mathrm{K}\right)\end{array}$

Houari Ameur

houari_ameur@yahoo.fr; ameur@cuniv-naama.dz

$\bowtie$ Siamak Hoseinzadeh

hoseinzadeh.siamak@gmail.com; siamak.hosseinzadeh@uniroma1.it

Extended author information available on the last page of the article 


$\begin{array}{ll}h & \text { Humidity } \\ P & \text { Pressure }(\mathrm{Pa}) \\ T & \text { Temperature }(\mathrm{K}) \\ t & \text { Time }(\mathrm{s}) \\ u, v & \text { Velocity components }\left(\mathrm{m} \cdot \mathrm{s}^{-1}\right) \\ x, y & \text { Cartesian coordinates } \\ \nu & \text { Viscosity }\left(\mathrm{m}^{2} \cdot \mathrm{s}^{-1}\right)\end{array}$

\section{Abbreviations}

ASHRAE American Society of Heating, Refrigerating and Air-Conditioning Engineers

CFD Computational fluid dynamics

FST Fixed setting temperature

GHG Greenhouse gas

HVAC Heating, ventilating, air-conditioning systems

ITD Information Technology Division

M.S.F.E Maximum solar flux on the east wall

M.S.F.H Maximum solar flux on the horizontal wall

M.S.F.W Maximum solar flux on the west wall

OPA Occupants' presence and actions

SVM Support vector machine

T.R.D. Technical Regulatory Documentation

\section{Introduction}

With today's needs for energy savings and control of the building's environmental impacts [1, 2], some doubts arise about the definition of thermal comfort and how to create and maintain comfort conditions as they are dependent on geographical location of building [3], as such person-to-person perceptions changes, and the type of activities performed. In situ studies of thermal comfort have revealed an overestimation of the level of perceived discomfort in reality compared to that predicted by regional building standards, especially in buildings that are air-conditioned during hot periods [4]. These studies served to lay the foundations for the adaptive approach, which characterizes thermal comfort through adaptive interactions between the environment and occupants. The use of standards can lead to a systemic alternative to air-conditioning [5], whereas the adaptive approach makes it possible to ensure thermal comfort with more modest energy consumption.

What differentiates the situation of modern architecture concerning the energy problem from the architecture of any other era is not only a decrease in the availability of energy resources but rather than the demand for thermal and environmental comfort parameters, which have only become extensive since the nineteenth century [6]. Homod et al. [3] discussed the importance of envelope materials used that determined the HVAC systems energy efficiency and presented hybrid model for thermal comfort evaluation in building. Sarafraz et al. [7] investigated the potential of concentrated hybrid PV/thermal system for production of steam and electricity. 
In addition, the energetic and exergy performance of a new configuration of liquid chemical looping gasification (LCLG) [8] and syngas production with supercritical biomass gasification [9] and investigations of toluene methylation to para-xylene [10]. There has been a significant shift in harnessing the heat and fluids conversion for various HVAC applications [11-15]. Last few years have been a significant shift in the maintenance of thermal comfort and adequate ventilation in buildings $[12,13,16]$, a period during which certain economic energy-cost issues and public awareness to the extension of comfort are being emphasized, allowing it to become a real challenge, both economically and socially. The development of thermal comfort techniques has played a paramount role to enlighten comfort parameters with various renewable energy technologies [17-19]. This epoch is characterized by the progress and enhancement of thermal machines [2]. It is imperative to mention that thermal comfort is also dependent on stress-free satisfaction of energy consumption, as such low-energy power generation [20, 21] with PV integrated solar thermal systems [22-24], advanced smart building wall insulation technologies and smart windows $[25,26]$ are growing in remote regions of the countries, where access to electric grid [27] is still under-development, and in fact a successful notion of smart cities with advanced insulation technologies where individual buildings could be self-energy reliant.

Nowadays, thermal comfort in buildings is a vital need due to its influence on the productivity and health of the occupant, occupants typically spend three-quarters of their time indoors. This requirement is supported by the standards of the Technical Regulatory Documentation (T.R.D.), which ensures that the indoor environment complies with the requirements of thermal comfort. However, the search for uniform and comfortable indoor thermal environments [15], following standards, throughout the year and without taking into account the particularities of the climate, the site, and the buildings, is accompanied by a multiplication of climatic installations, resulting in high-energy consumption, mainly of fossil fuel dependent areas which is exhaustible and polluting, for which solar energy systems integration, a standalone wind power plant, small scale parabolic trough-based solar energy generators [28] and the hybridization of PV system [29, 30] with it are being explored.

Over the last 30 years, energy consumption in Algeria has been steadily increasing in the residential sector, still leading the other sectors. In 2004, this sector accounted for $43.5 \%$ of national final energy consumption. Besides, it was responsible for more than $20 \%$ of greenhouse gas (GHG) emissions. Air-conditioning load and energy requirement have also been rising burden specifically since last decade, particularly after the heatwave in the summer of 2003 following the acceleration of global warming due to the increase in GHG emissions.

In this research, we are interested in the analytical aspect of thermal comfort as a complement to the simulated element, which provides a global vision of thermal comfort in buildings. Based on a bibliographical study on thermal comfort and existing methods, we conducted a numerical study in situ in a room of office building to explore adaptive comfort more closely and characterize the interaction between comfort quantities. By using Aripak software and during the summer season, Mousavi Motlagh et al. [2] studied an air-conditioned class that was affected by two factors: cold jet and the buoyancy force of the heat source. Sempey et al. [31] made 
a rapid simulation of the temperature distribution in conditioned rooms. They used the appropriate orthogonal decomposition. On the other hand, Trabelsi et al. [32] studied coupled heat and moisture transfers in building envelopes, which revealed the importance of considering these phenomena at the wall scale for a good assessment of the behavior of indoor environments and a better prediction of the overall performance of air-conditioned buildings. First, heat and moisture transfer modeling was undertaken. This model was then implemented under "Matlab-Simulink" and then validated using various validation tools.

Rebai et al. [33] have studied the variation of the location (height above floor level) of the extracting unit on the interpretation of velocity and temperature in the room by varying the supply velocity of air (between $0.8 \mathrm{~m} \cdot \mathrm{s}^{-1}$ and $0.2 \mathrm{~m} \cdot \mathrm{s}^{-1}$ ). Then, they studied the impact of the Archimedean number on the dynamic and thermal properties of air at the entrance of the room (velocity and temperature) to compare the results obtained with the Fluent software with those obtained with the model developed and used by Xue and Shu [34].

Lin and Liao [35] analyzed the temperature and velocity variation in an airtrained area. The heating sources produced by five personal computer and distributing cooling fan in an air-conditioned room are reviewed in this research. The experimental analyses are carried out to evaluate the alternatives with the mathematical simulation, and the results have shown acceptable agreements in temperature distribution. The results exhibit the interval of steady time is reduced while circulating fan functioning. A standard temperature for the event without having a circulating fan is reduced than that of a moving fan. However, global earth temperature distribution is not homogeneous, and localized temperature has followed the similar pattern. Mebarki et al. [36] carried out a study of the dimensioning of a ventilation and air conditioning installation at the Béchar Airport, taking into account the difference in humidity between the supply air and the environment to be air-conditioned. The latter has an air-conditioning system represented by air-conditioning cabinets; it subsequently led us to make a comparison from a system and cost point of view between the two systems. To do this, they had developed a software package under the MATLAB® SIMULINK environment based on an international method for estimating different air conditioning loads. Alahmer et al. [37] analyzed the thermal sensation and the state of the comfort of vehicle cabins, under control of relative humidity and temperature, using the Berkeley and Fanger models. It shows that controlling relative humidity with dry temperature control allows the cab to reach the comfort zone more quickly than dry temperature cab control alone for the heating and cooling processes. Schminder and Gårdhagen [38] presented a numerical model to predict human performance and thermal conditions in cockpits, and a significant effect of thermal comfort on the mental and physical degradation of crew members was reported.

Nada et al. [39] inspected the efficiency of hybrid air conditioning and water heating systems and humidification-dehumidification proposed for water production and power conservation in dry and hot climatic zones. The evaluation was achieved to characterize the configurations systems with the most significant freshwater production rate, the highest energy savings, and the highest total cost savings. An advanced correlation was developed and utilized to determine the rate of 
freshwater production and total system energy consumption in control parameters. Zhou et al. [40] defined a data-based thermal comfort model using vector machine support algorithms: ASHRAE (American Society of Heating, Refrigerating and AirConditioning Engineers) RP-884 database overview. They used the support vector machine (SVM) algorithm and the RP-884 thermal comfort database for the development of a new model with self-learning and self-correction capabilities.

Using the heating behavior of the occupants and skin temperatures, Katic et al. [41] developed a self-learning algorithm to predict global thermal comfort. It explored the new configuration of inputs like the utilization of skin temperature and custom heating system parameters as constraints to indicate personal thermal easiness.

Wang et al. [42] performed a dimensional analysis of subjective thermal comfort parameters based on the ASHRAE global thermal comfort database. This study focuses on the thermal experience of the occupants. Prediction accuracy was $87 \%$ for thermal acceptability and $64 \%$ for thermal preference. Prediction error may be due to individual differences in occupants and to errors in a survey response. These results could help design chamber experiments, field studies, and human-building interaction interfaces by highlighting the choice of subjective thermal measurements to collect information on the occupants' thermal experience.

Larsen et al. [43] developed a tool for the holistic evaluation of potential indoor environmental quality. Carlucci et al. [44] made a model of occupant behavior in buildings. They reviewed approaches related to OPA (occupants' presence and actions) modeling in structures. Pérez-Lombard [45] inspected available information regarding power input in buildings, and primarily related to HVAC (heating, ventilating, air-conditioning) systems. They performed comparisons between commercial buildings for various countries. $\mathrm{Xu}$ et al. [46] conducted simulations of DST in a public building in Changsha (China) based on meteorological data of 2017. Their results revealed that the use of DST might save up to $65.5 \%$ of power input compared with the traditional fixed setting temperature (FST).

For an office building in a subtropical climate, Chowdhury et al. [47] examined the effect of different low-energy cooling-technologies (chilled ceiling) on the thermal comfort. For summer and winter seasons, they evaluated the thermal conditions of the Information Technology Division (ITD) building at Central Queensland University. Gjerland et al. [48] employed a scoping review method to map the field of empirical research on office concepts. Peeters et al. [49] evaluated the comfort values and scales in residential houses. They focused on comfortable temperature levels in the room more than on the detailed temperature distribution within that room. Stavrakakis et al. [50] determined the thermal comfort by natural cross-ventilation in buildings. They inspected the natural cross-ventilation with openings at non-symmetrical locations. They measured the velocity and temperature selected positions in the room.

To perform experiments in a climate chamber, Katic et al. [51] employed two different approaches based on the output data (thermal sensation and thermal comfort votes), and five different sets of input variables were explored. The results showed that personal comfort models among all tested approaches and subjects revealed the best median accuracy of 0.84 . The authors recommended performing 
more experiments due to the limited number of test subjects in their study. Sakhri et al. [52] carried out an experimental investigation on the performance of a coupled system: an earth-to-air heat exchanger and a solar chimney. The obtained results showed that the new system created two main thermal regimes in the same day. It was also observed that the system increases the outlet air relative humidity by $46 \%$ due to the condensation phenomena and reduces it sometimes by $45 \%$. The recent model made of the two techniques was able to produce between $3 \mathrm{~W}$ and $20 \mathrm{~W}$ of heating/cooling capacity at the outlet of the system. Koçyiğit [53] performed an investigation of the thermal and strength properties of a novel composite developed for insulation as building material. They tried to produce novel composite materials, which provide thermal insulation using waste and natural materials in construction applications. Mui et al. [54] reviewed and categorized the significant developments and trends in thermal comfort research in recent years. Based on the research gaps identified, a practical solution was proposed to improve the reliability of thermal comfort predictions. Two Bayesian updating protocols, namely individual updating and global updating, were put forward.

In the present paper, the thermal comfort inside a building in a hot-arid area is investigated. The region of Bechar is taken as a case study. Two factors are used to determine thermal comfort, namely temperature and humidity. This paper contributes: a description of the problem and the site of the study is discussed in Sect. 2; the method of investigation, and the required details, such as the governing equations and boundary conditions, are presented in Sect. 3; mesh tests and validation of predicted results are detailed in Sect. 4; and the results are shown in terms of velocity, streamlines, temperature, isotherms, and profiles of moisture. For indoor comfort evaluation, a computer program was created with Delphi language; it allows treating the temperature and moisture coupling. The program plots the points on the humid air diagram and provides contemplated percentage of the points that are in the comfort zones.

\section{Problem Description}

The location under consideration is integrated into office building, where occupants perform administrative services. A selected office has a volume of $45 \mathrm{~m}^{3}$. The walls that have heat exchanges with the outside are the east, west, and ceiling. Considering the other walls are adiabatic and therefore neglecting heat exchanges with the neighboring locations. The heat balance was carried out using the regulatory technical document method (DTR), with a supply airflow rate $q_{\text {souf }}=0.19 \mathrm{~m}^{3} \cdot \mathrm{s}^{-1}$. The heat balance details of the office are provided in Fig. 1.

\section{The Governing Equations [55]}

- Continuity equation 


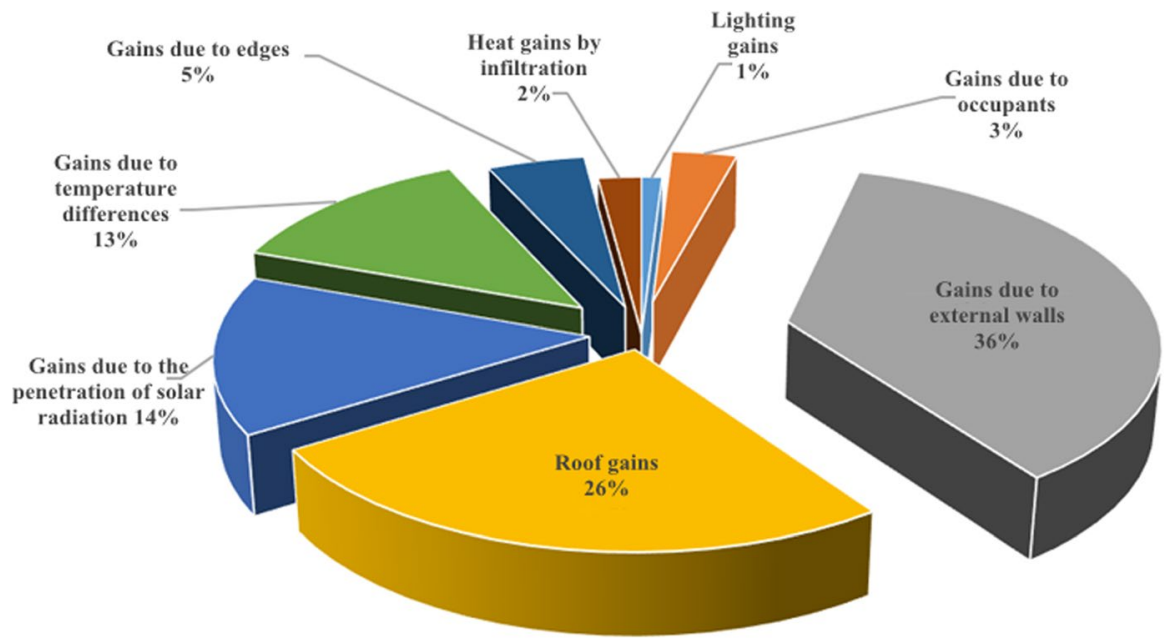

Fig. 1 Heat balance details of the office

$$
\frac{\partial \rho}{\partial t}+\operatorname{div}(\rho u)=0
$$

- Momentum equations

$$
\begin{aligned}
& \frac{\partial u}{\partial t}+u \frac{\partial u}{\partial x}+v \frac{\partial u}{\partial y}=-\frac{1}{\rho} \frac{\partial p}{\partial x}+v\left(\frac{\partial^{2} u}{\partial x^{2}}+\frac{\partial^{2} u}{\partial y^{2}}\right)+S_{i} \\
& \frac{\partial v}{\partial t}+u \frac{\partial v}{\partial x}+v \frac{\partial v}{\partial y}=-\frac{1}{\rho} \frac{\partial p}{\partial y}+v\left(\frac{\partial^{2} v}{\partial x^{2}}+\frac{\partial^{2} v}{\partial y^{2}}\right)+S_{j}
\end{aligned}
$$

- Heat equation

$$
k\left(\frac{\partial^{2} T}{\partial x^{2}}+\frac{\partial^{2} T}{\partial y^{2}}\right)+f(t, i, \delta, a, \psi)=\frac{\partial T}{\partial t} \rho \cdot C p
$$

\section{Initial and Boundary Conditions}

The computational fluid dynamics (CFD) method has proved its efficiency in various engineering applications and with complex geometries [56-65]. In this works, the CFD tool Fluent was used to perform the investigation. This computer software is based on the finite volume method to solve the governing equations.

The initial and boundary conditions are applied to the office location (Fig. 2), as follows: 


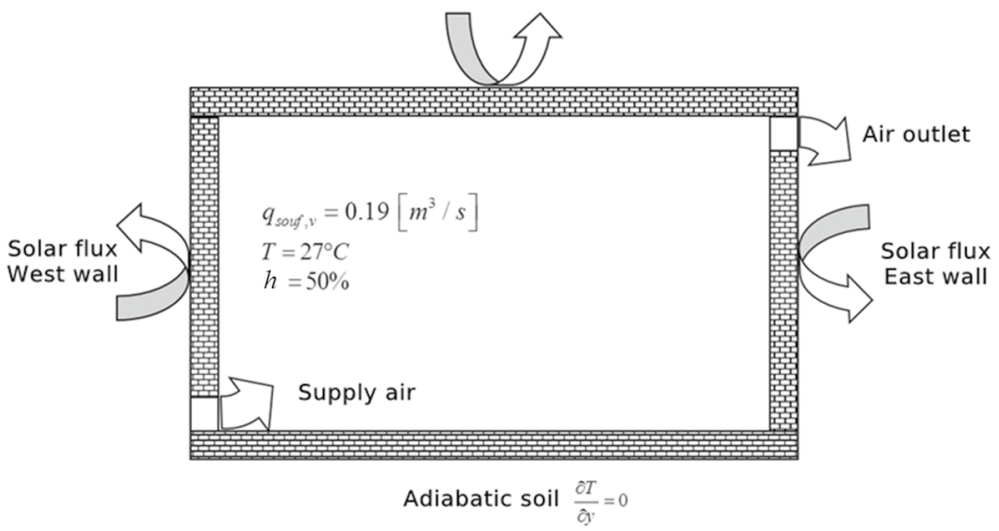

Fig. 2 Boundary conditions applied to the office location illustrates the heat exchanges

At the time $t=0$, the outdoor temperature is $T=44{ }^{\circ} \mathrm{C}$ (the basic outdoor conditions for the Bechar D1 zone (D.T.R 3-4)). The indoor temperature is the difference between the basic outdoor temperature and the indoor temperature (according to D.T.R) room. At the initial time $t=0$, the indoor and outdoor humidity $h=14 \%$ is applied. However, and for $t>0$, the indoor humidity is $50 \%$, while the outdoor humidity remains $14 \%$.

At the time $t>0$, for the walls:

- East wall $\left(90^{\circ}\right.$ with the south $\left.\left(0^{\circ}\right)\right)$, vertical $\left(90^{\circ}\right.$ with the horizontal plane) subjected to a solar flux calculated numerically with the ASHRAE method.

- West wall $\left(90^{\circ}\right.$ with the south $\left.\left(0^{\circ}\right)\right)$, vertical $\left(90^{\circ}\right.$ with the horizontal plane) subjected to a solar flux calculated numerically with the ASHRAE method.

- The roof $\left(0^{\circ}\right.$ with the horizontal plane) subject to a solar flux calculated numerically with the ASHRAE method.

- The floor is considered adiabatic $\partial T / \partial y=0$

Variations of the solar fluxes on the East wall, West walls, and on the roof are presented in Fig. 3. Mesh dependency tests were also carried out for various sizes of grid elements, as shown in Fig. 4. Detailed information of the different meshes investigated is summarized in Table 1. From the obtained results, it seems that mesh 4 is the most accurate. Therefore, it has been selected for all calculations. The computations were performed with a computer machine having Intel Core i7-950 CPU 1, 8 threads base clock $3.05 \mathrm{GHz}$, and RAM $18 \mathrm{~GB}$. We note that the residual target for the convergence has been fixed at $10^{-5}$. 


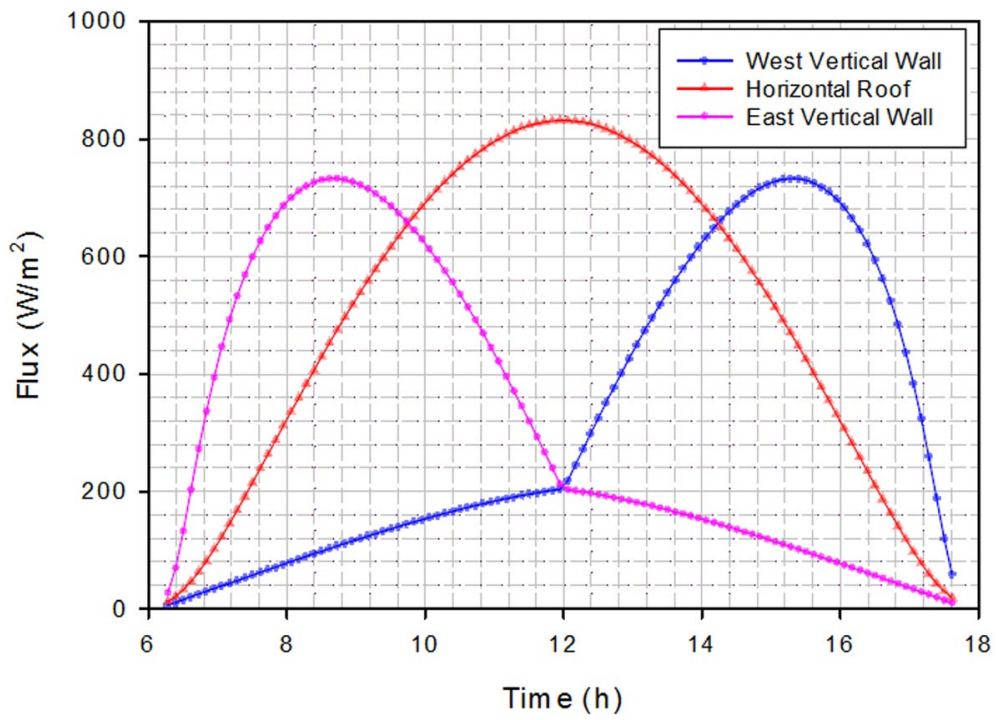

Fig. 3 Solar flux in the region of Bechar, for (a) an east-facing vertical wall, (b) a west-facing vertical wall, (c) a horizontal roof

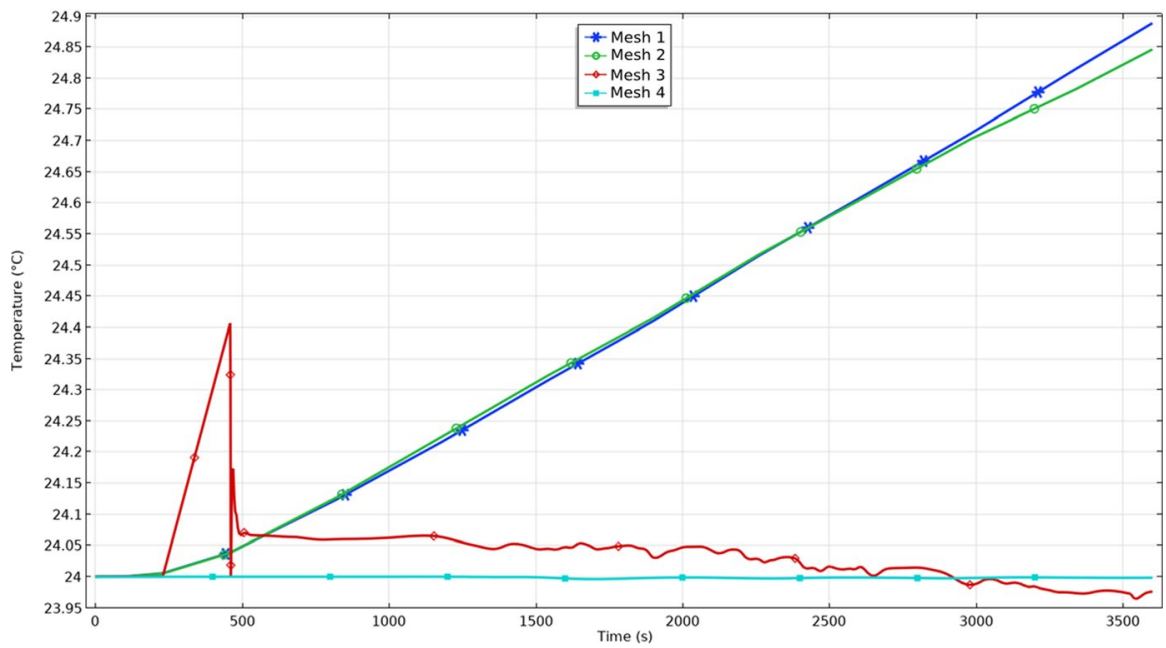

Fig. 4 Mesh tests 
Table 1 Details on the mesh tests

\begin{tabular}{llll} 
Mesh 1 (coarse) & Mesh 2 (normal) & Mesh 3 (extra fine) & $\begin{array}{l}\text { Mesh 4 } \\
\text { (extremely } \\
\text { fine) }\end{array}$ \\
\hline 0.54 & 0.362 & 0.108 & 0.054 \\
0.0108 & 0.00162 & $4.05 \times 10^{-4}$ & $1.08 \times 10^{-4}$ \\
1.4 & 1.3 & 1.2 & 1.1 \\
0.4 & 0.3 & 0.25 & 0.2 \\
1.0 & 1.0 & 1.0 & 1.0
\end{tabular}

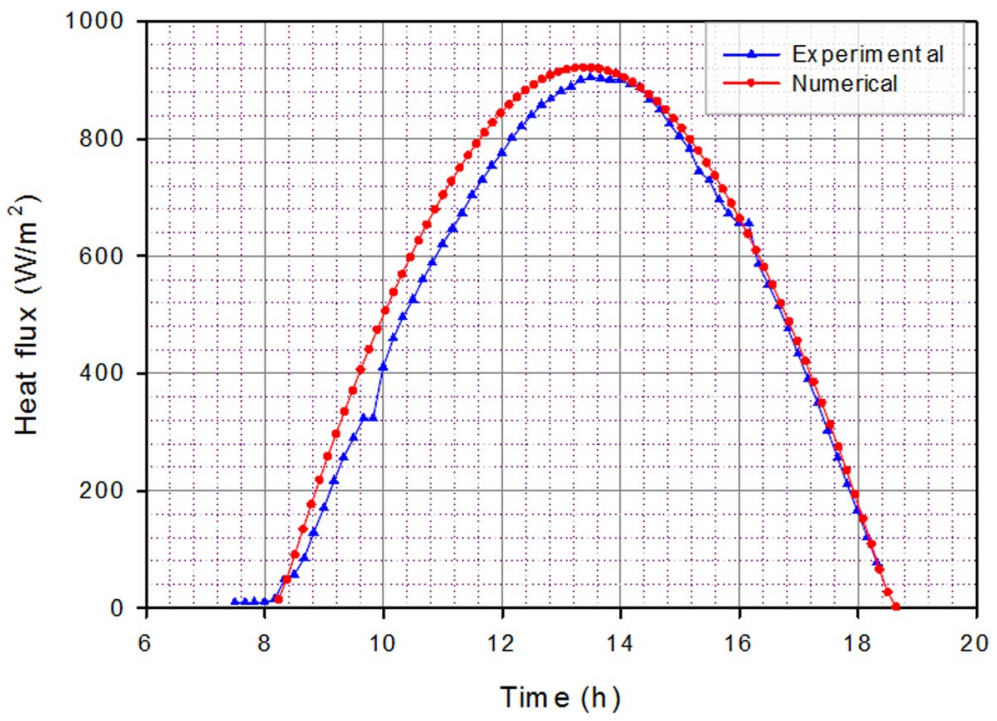

Fig. 5 Heat flux vs. time: validation of the predicted results

\section{Validation}

The ENERGARID laboratory (Laboratory of Energetic in Arid Zones) of the University of Bechar is equipped with a meteorological station, which provides us with meteorological data for the validation of our simulation. The numerical computations are based on calculation methods similar to Lui \& Jordan, and ASHRAE. Figure 5 presents the variation of the solar flux during the day of 08/08/2011. This figure provides a comparison between the results obtained from the meteorological data and those predicted numerically. As observed, the comparison shows a satisfactory agreement. 
(a)

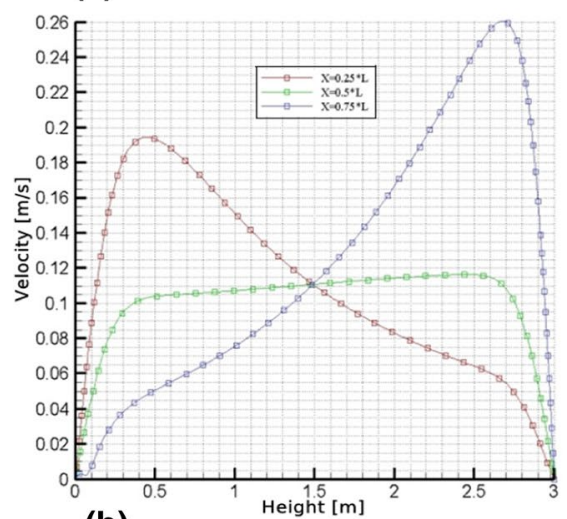

(b)

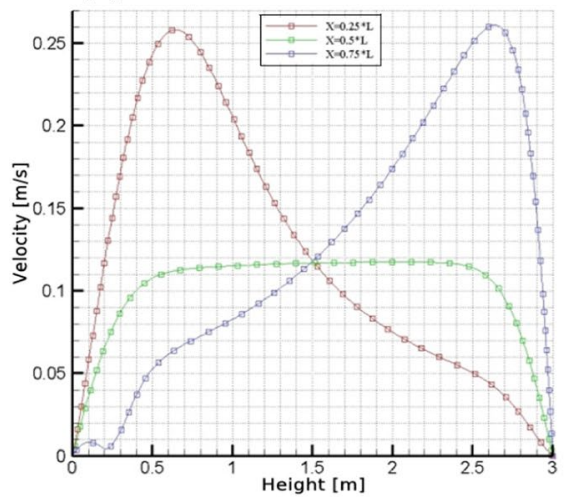

(c)

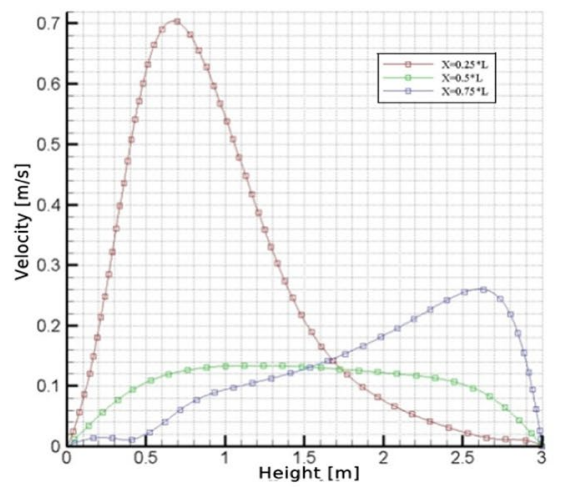

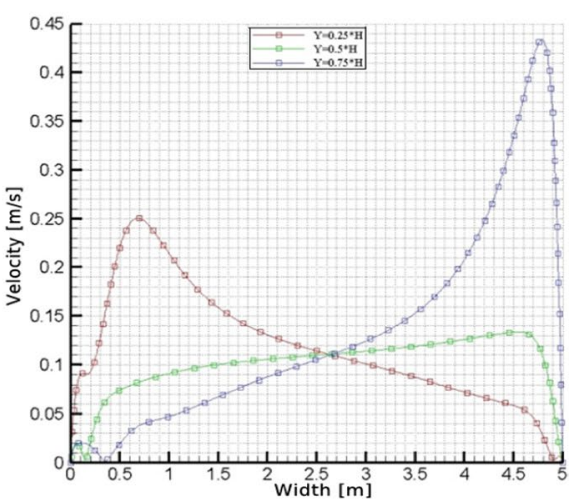
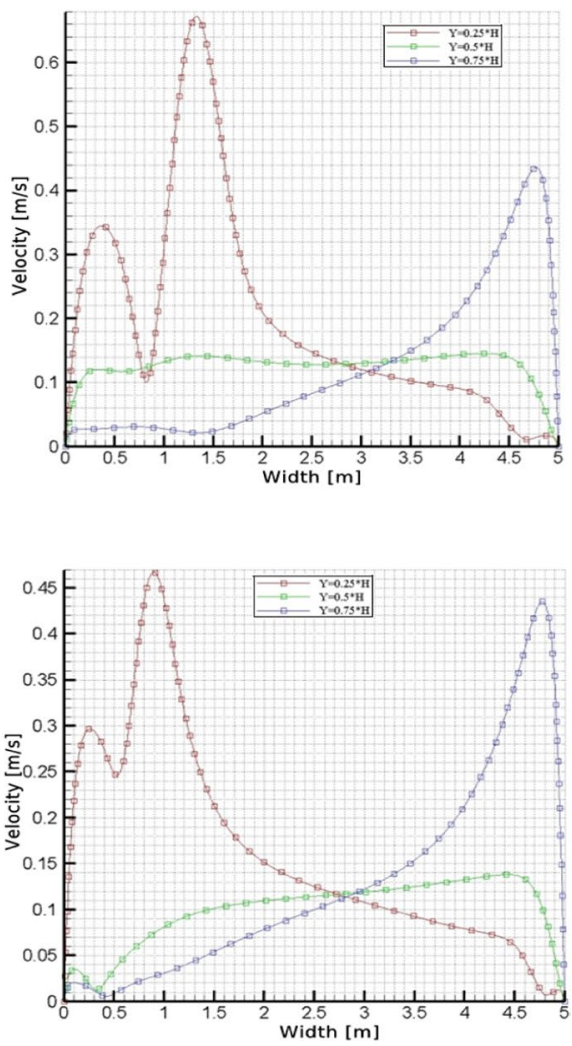

Fig. $6 u$ and $v$ velocities for the maximum flux, (a) at east wall, (b) at the roof, (c) at west wall 


\section{Results and Discussion}

\subsection{Flow Fields}

The velocity along the $x$-axis is presented in Fig. 6 (at the left side) for three positions: $0.25 \times H, 0.5 \times H$, and $0.75 \times H$. In addition, the velocity along the $y$-axis is presented in Fig. 6 (at the right side) for three heights: $0.25 \times L, 0.5 \times L$, and $0.75 \times L$.

For the velocity profiles along the three axes, it is noted that in the $x$-axis $=0.75 \times H$ speed is maximum near the roof. For the velocity profiles along the three-axis (Fig. 6a, at the left side), the velocity increases with the increase in the height until it reaches its maximum near the walls. This increase is due to the gradient of heat.

Air flow velocity applied between $0.02 \mathrm{~m} \cdot \mathrm{s}^{-1}$ and $0.26 \mathrm{~m} \cdot \mathrm{s}^{-1}$, which are comfortable for the occupants and satisfactory to the human thermal comfort conditions. Most studies confirm that these values are the best to provide thermal comfort in a residential house or an office where the activity does not require a hard effort. From the velocity profiles, the same is observed in Fig. $6 \mathrm{~b}$ (at the left side), which disappears over time. The highest velocity that is observed at the top of the curve in Fig. 6c is due to the temperature gradient near the roof, where the temperature is considerably high.

From the $y$-velocity profiles, an unchanging velocity value is observed at the level $y=0.5 \times L$. The air velocity inside the building changes with height and near the walls. The highest values of velocity are observed near the walls due to the buoyancy effect, which results from the temperature gradient.

The streamlines are plotted in Fig. 7 for the maximum solar flux at three locations: east wall, the roof, and the west wall. Inside the office, the air flows are homogeneous. This latter gives a comfortable sensation, and the air distribution inside prevents creating a dead zone. This is why the streamlines are almost the same; even the solar flux for the three sides (east-wall, roof, and west-wall) is different.

(a)

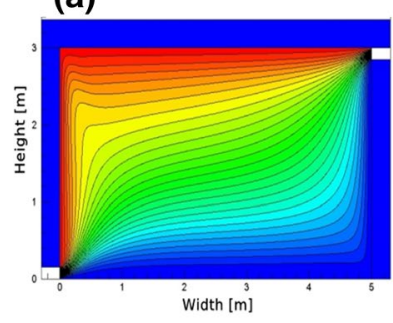

(b)

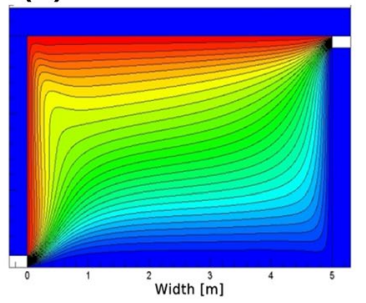

(c)

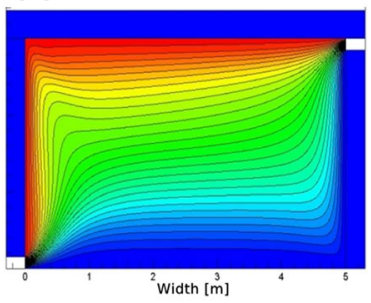

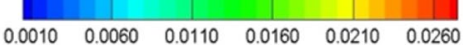

Fig. 7 Streamlines $\left(\mathrm{m} \cdot \mathrm{s}^{-1}\right)$ for a maximum flux, (a) at east wall, (b) at roof, (c) at west wall 
(a)

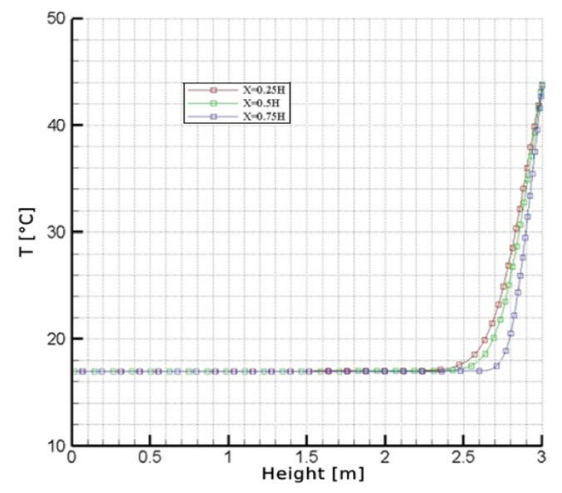

(b)

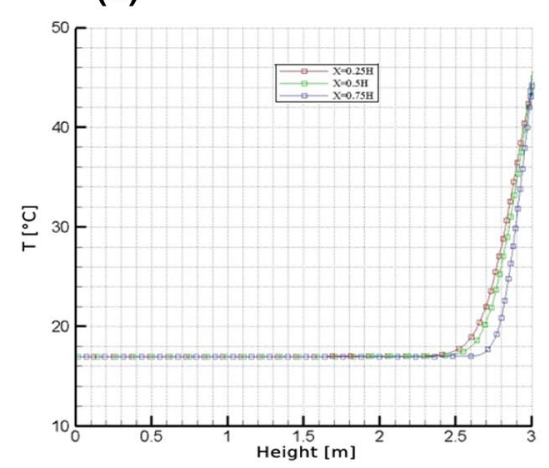

(c)

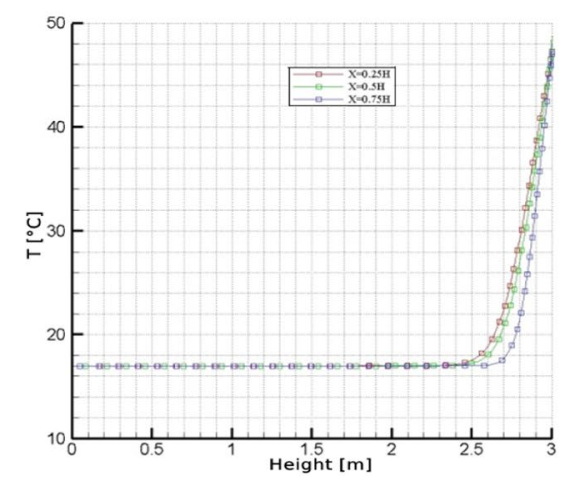

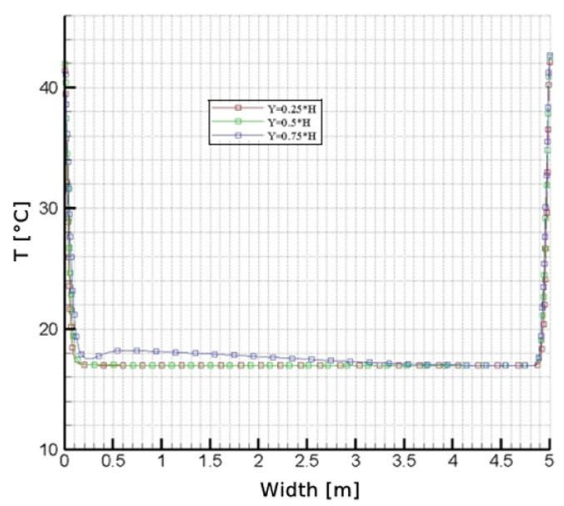
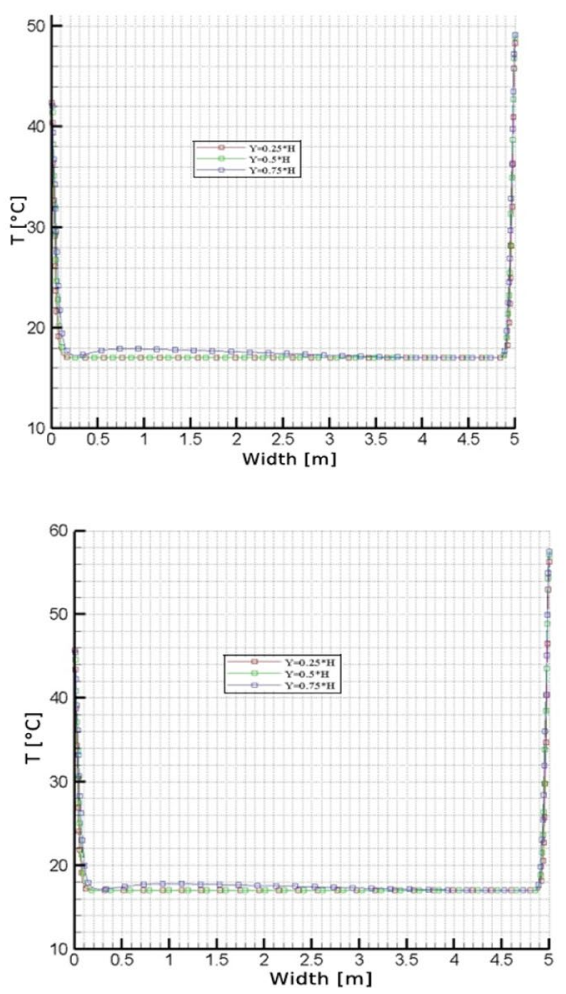

Fig. 8 Temperatures for Max. flux, at (a) east wall, (b) roof, (c) west wall

\subsection{Thermal Fields}

Figure 8 (left side) represents the temperatures for (a) maximum solar flux on the east wall (M.S.F.E), (b) maximum solar flux on the horizontal wall (M.S.F.H), and (c) maximum solar flux on the west wall (M.S.F.W). We notice a stratification with 
(a)

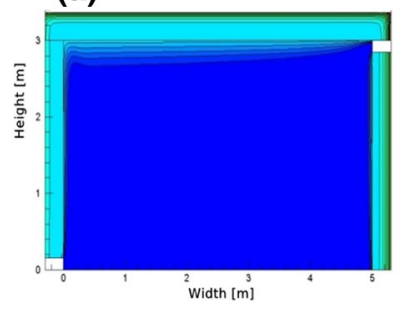

(b)

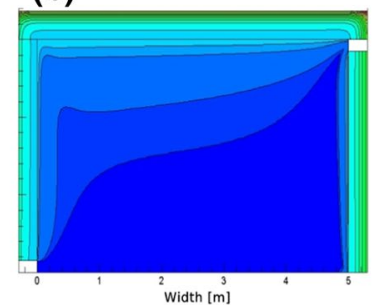

(c)

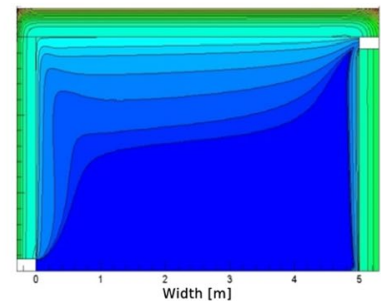

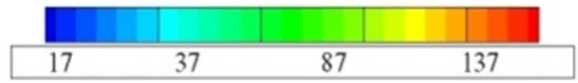

Fig. 9 Isotherms for the walls: (a) east, (b) horizontal, (c) west

an increase in temperature near the Horizontal wall. Figure 8 (right side) exhibits an isothermal stratification; there is an increase in the temperature on the vertical walls.

The stratification of the temperature reveals the thermal comfort inside the building. That creates a human comfort space as we can move without thinking to look for a thermal comfort zone. Near the wall, the temperature increases due to the conduction of solar radiation through the wall.

Figure 9 represents the isotherms for (a) maximum solar flux on the east wall (M.S.F.E), (b) maximum solar flux on the horizontal wall (M.S.F.H), and (c) maximum solar flux on the west wall (M.S.F.W). We notice a stratification with an increase in temperature near the horizontal fence. It is pertinent to mention that the hot air temperature increases due to its lower density and the cold air decreases due to its high density. The same variation of the temperature occurs for the three sides of the office, which indicates that the thermal comfort covers the building, as shown in Fig. 9.

(a)

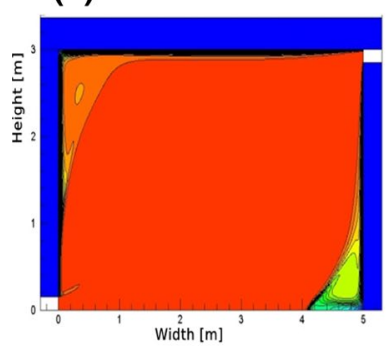

(b)

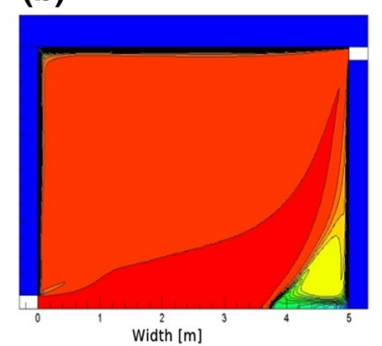

(c)

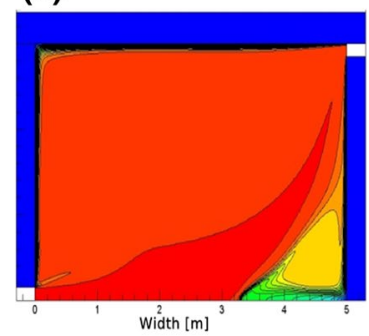

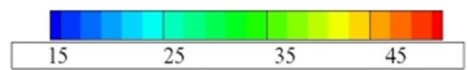

Fig. 10 Humidity for the maximum flux at (a) east wall, (b) roof, (c) west wall 
(a)

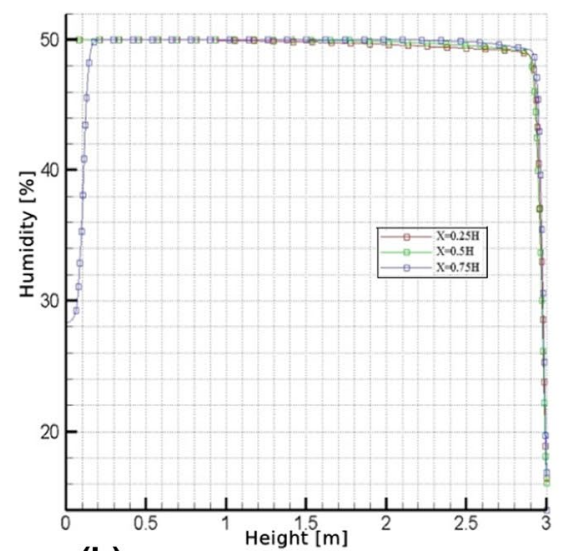

(b)

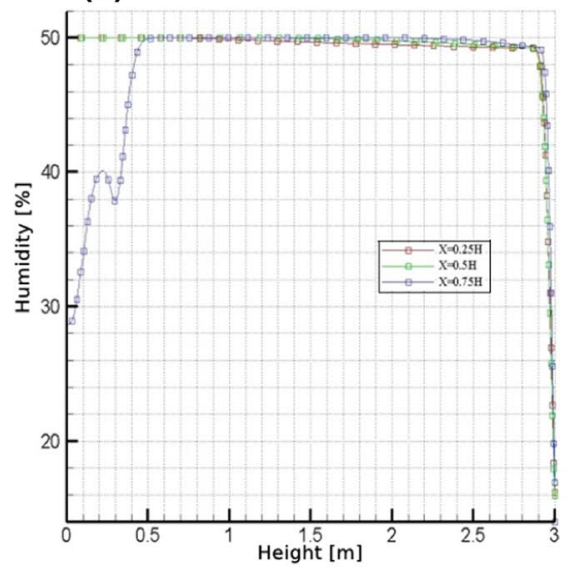

(c)

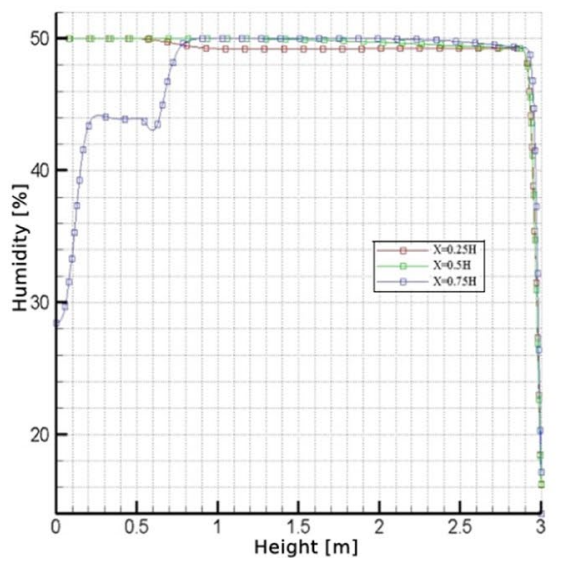

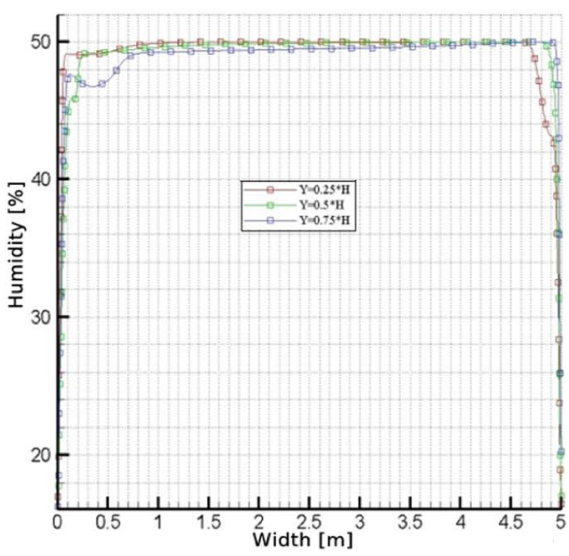
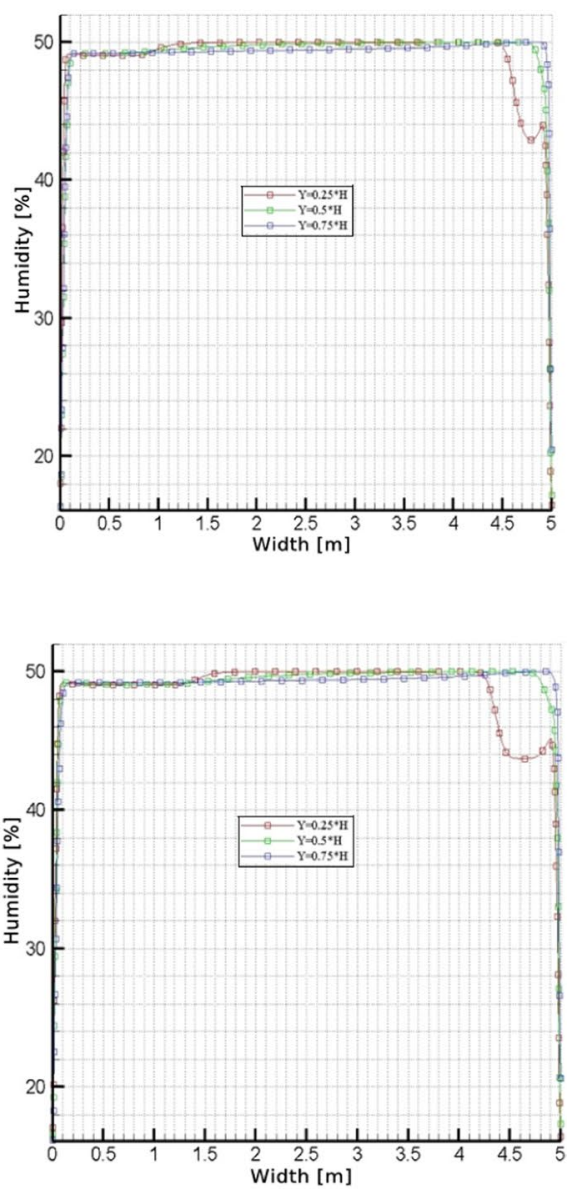

Fig. 11 Humidity for the maximum flux, at (a) east wall, (b) roof, (c) west wall 


\subsection{Humidity}

The spatial distribution of humidity is given in Fig. 10 for each side of the building. Humidity has a significant impact on thermal comfort. For the best support, the relative humidity should be between $30 \%$ and $60 \%$. In an outside range of this range, dry air may produce some phenomena of static electricity. It reduces plant growth, dries up the skin, and irritates the respiratory mucosa. Figure $10 \mathrm{a}-\mathrm{c}$ confirms the stratification and also the recirculation at a high level. The values of humidity in these figures change within the required thermal comfort. Some recirculation loops are observed at the lower corner of the building, the so-called dead zones, where the velocity is low. These regions have not a considerable effect on the thermal comfort for the whole volume of the building. The most significant impact of dead zone creation is the low air velocity since the air saturated with moisture is heavy.

Profiles of the humidity along the $x$-axis are plotted in Fig. 11 (at the left side) for three locations: $0.25 \times H, 0.5 \times H$, and $0.75 \times H$. The variation of humidity along the $y$-axis is presented in Fig. 11 (at the right side) for three locations: $0.25 \times L, 0.5 \times L$, and $0.75 \times L$.

As illustrated in these resents as shown in Fig. 10, the relative humidity varies between $30 \%$ and $50 \%$, which means that the office is thermally comfortable. The decay in curves is yielded by the dead zones where the flow velocity is too low. Even the walls' temperature changes gradually with the variation of solar radiation, the humidity remains in the required range of thermal comfort.

\subsection{Thermal Comfort}

As mentioned above, a computer program has been built to present the temperature-humidity in a psychrometric diagram. There are four regions in the chart: the first one, the high thermal comfort where the couple of humidity and temperature changes between $35 \%$ and $55 \%$ at $24^{\circ} \mathrm{C}$ and $27{ }^{\circ} \mathrm{C}$, respectively. The second region
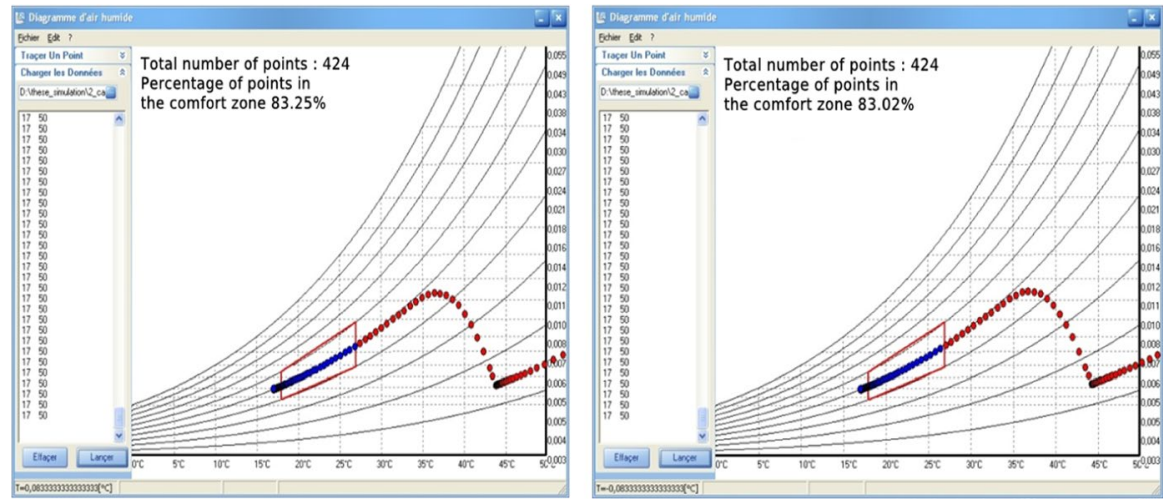

Fig. 12 Temperature $\left[{ }^{\circ} \mathrm{C}\right]$ and relative humidity [\%] along a vertical axis $X=0.5 \times L$ 
(a)

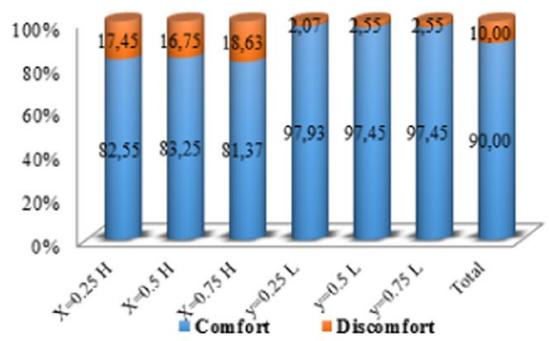

(b)

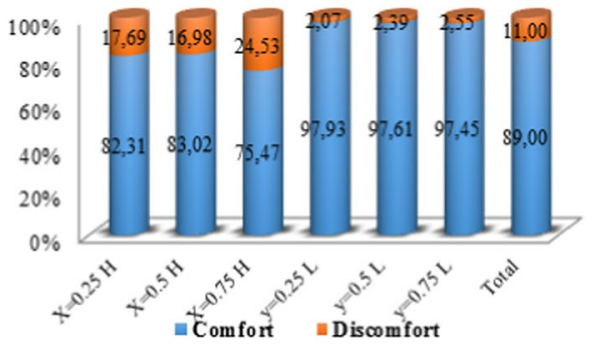

(c)

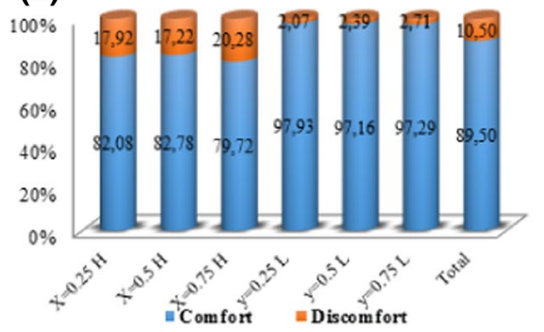

Fig. 13 The points are located in the comfort zone for the maximum solar flux at: (a) east wall, (b) the roof, (c) west wall

concerns acceptable thermal comfort, while the third region is that of the respiratory difficulty, for which the temperature exceeds $35{ }^{\circ} \mathrm{C}$ and the relative humidity does go over $14 \%$, like the case of our studied region (Bechar). However, the fourth region is the suffocation zone, where the temperature exceeds $35^{\circ} \mathrm{C}$, and the relative humidity exceeds $45 \%$. From the results provided in Fig. 12, it is observed that the maximum values of the points are located in the comfort zone and that for the maximum solar flux at each side of the building.

For further details, the values of temperature and humidity are presented in Fig. 13 at different locations in the studied building. As mentioned above, most of the points of temperature-humidity are located in thermal comfort region.

\section{Conclusion}

The thermal comfort and humidity of the office in an arid hot-arid environment of Bechar, located in the northwestern region of Algeria, were investigated at the variation of moisture and temperature one beside the other. For the best evaluation of the thermal comfort, a program in Delphi language was elaborated. Through this program, the couple (relative humidity and temperature) was plotted as a point in the diagram. The obtained results revealed that thermal comfort, especially in arid regions, does not depend only on the temperature but also and considerably on the humidity. Furthermore, the flow velocity also has a significant impact on thermal comfort. The results showed that $90 \%$ of points are situated in the thermal 
comfort zone. The internal air velocity should be in the range between $0.2 \mathrm{~m} \cdot \mathrm{s}^{-1}$ and $0.3 \mathrm{~m} \cdot \mathrm{s}^{-1}$ for buildings with regular use. It is recommended that further studies on thermal comfort and occupant perception of climate and behaviors in such hot-arid regions are needed.

Funding Open access funding provided by Università degli Studi di Roma La Sapienza within the CRUICARE Agreement.

Open Access This article is licensed under a Creative Commons Attribution 4.0 International License, which permits use, sharing, adaptation, distribution and reproduction in any medium or format, as long as you give appropriate credit to the original author(s) and the source, provide a link to the Creative Commons licence, and indicate if changes were made. The images or other third party material in this article are included in the article's Creative Commons licence, unless indicated otherwise in a credit line to the material. If material is not included in the article's Creative Commons licence and your intended use is not permitted by statutory regulation or exceeds the permitted use, you will need to obtain permission directly from the copyright holder. To view a copy of this licence, visit http://creativecommons.org/licen ses/by/4.0/.

\section{References}

1. S. Hoseinzadeh, M. Hadi Zakeri, A. Shirkhani, A.J. Chamkha, J. Renew. Sustain. Energy 11, 015103 (2019)

2. S.F. Mousavi Motlagh, A. Sohani, M. Djavad Saghafi, H. Sayyaadi, B. Nastasi, Energies 14, 636 (2021)

3. R.Z. Homod, A. Almusaed, A. Almssad, M.K. Jaafar, M. Goodarzi, K.S.M. Sahari, J. Energy Storage 34, 101975 (2021)

4. N. Sakhri, Y. Menni, H. Ameur, A.J. Chamkha, N. Kaid, M. Bensafi, G. Lorenzini, O.D. Makinde, J. Mech. Eng. Sci. 14, 7109 (2020)

5. A. Sohani, H. Sayyaadi, Appl. Therm. Eng. 123, 1396 (2017)

6. S. Memon, In Sustainable Development on Building and Environment: Proceedings of the 7th International Conference, London South Bank University (2015).

7. M.M. Sarafraz, M. Goodarzi, I. Tlili, T.A. Alkanhal, M. Arjomandi, J. Therm. Anal. Calorim. 143, 1389 (2021)

8. M. Sarafraz, M. Safaei, A. Leon, U. Khaled, M. Goodarzi, R. Meer, Processes 7, 763 (2019)

9. M.M. Sarafraz, M.R. Safaei, M. Jafarian, M. Goodarzi, M. Arjomandi, Energies 12, 2591 (2019)

10. M. Abdi-khanghah, A.A.A.A. Alrashed, T. Hamoule, R.M. Behbahani, M. Goodarzi, J. Therm. Anal. Calorim. 135, 1723 (2019)

11. A.A. Alanezi, M.R. Safaei, M. Goodarzi, Y. Elhenawy, Energies 13, 2824 (2020)

12. S. Mehrdad, R. Dadsetani, A. Amiriyoon, A.S. Leon, M. Reza Safaei, M. Goodarzi, Processes 8, 264 (2020)

13. M. Deymi-Dashtebayaz, S. Maddah, M. Goodarzi, O. Maddah, J. Therm. Anal. Calorim. 141, 361 (2020)

14. S. Maddah, M. Goodarzi, M.R. Safaei, Alex. Eng. J. 59, 4037 (2020)

15. Z. Li, M.M. Sarafraz, A. Mazinani, H. Moria, I. Tlili, T.A. Alkanhal, M. Goodarzi, M.R. Safaei, Energy Convers. Manag. 222, 113230 (2020)

16. M. Dhahri, S. Nekoonam, A. Hana, M. El Haj Assad, M. Arıcı, M. Sharifpur, H. Sammouda, J. Therm. Anal. Calorim. https://doi.org/10.1007/s10973-020-10248-2 (2020)

17. H. Kariman, S. Hoseinzadeh, P.S. Heyns, Case Stud. Therm. Eng. 16, 100548 (2019)

18. A. Sohani, S. Hoseinzadeh, K. Berenjkar, J. Energy Storage 33, 101862 (2021)

19. S. Hoseinzadeh, R. Azadi, J. Renew. Sustain. Energy 9, 045101 (2017)

20. S. Hoseinzadeh, M.H. Ghasemi, S. Heyns, Renew. Energy 160, 323 (2020)

21. S. Hoseinzadeh, P. Stephan Heyns, J. Energy Resour. Technol. 143, 082106 (2021) 
22. A. Radwan, T. Katsura, S. Memon, E.M. Abo-Zahhad, O. Abdelrehim, A.A. Serageldin, M.R. Elmarghany, A. Khater, K. Nagano, Sustain. Energy Fuels 4, 6251 (2020)

23. A. Radwan, T. Katsura, S. Memon, A.A. Serageldin, M. Nakamura, K. Nagano, Energy Convers. Manag. 215, 112920 (2020)

24. S. Memon, P.C. Eames, J. Daylighting 4, 15 (2017)

25. T. Katsura, S. Memon, A. Radwan, M. Nakamura, K. Nagano, Sol. Energy 199, 326 (2020)

26. S. Hoseinzadeh, Micro Nanosyst. 11, 154 (2019)

27. A. Khan, S. Memon, T.P. Sattar, IEEE Access 6, 26404 (2018)

28. S.A. Makkeh, A. Ahmadi, F. Esmaeilion, M.A. Ehyaei, J. Clean. Prod. 273, 123122 (2020)

29. A. Ahmadi, M.A. Ehyaei, D.H. Jamali, M. Despotovic, F. Esmaeilion, A. Abdalisousan, E.B. Hani, J. Clean. Prod. 280, 124322 (2021)

30. A. Sohani, H. Sayyaadi, Energy Convers. Manag. 224, 113291 (2020)

31. A. Sempey, C. Inard, C. Ghiaus, C. Allery, Build. Environ. 44, 280 (2009)

32. A. Trabelsi, R. Belarbi, M. Qin, Congrès SFT09 1-6 (2009)

33. B. Rebai, M.S. Rouabah, Z.A. Mehri, Séminaire Int. sur le Génie Clim. Energ. SIGCLE’2010, 4-7 (2010)

34. H. Xue, C. Shu, Build. Environ. 34, 245 (1998)

35. C.N. Lin, C.H. Liao, International Symposium on Computer, Communication, Control and Automation (3CA), vol. 2, p. 29 (2010)

36. B. Mebarki, B. Draoui, B. Allaoua, M. Lamari, M.R. Ferrad, Sém. Int. Génie Clim. Energ. (SIGCLE'2010) 2-6 (2010)

37. A. Alahmer, M. Omar, A.R. Mayyas, A. Qattawi, Build. Environ. 48, 146 (2012)

38. J. Schminder, R. Gårdhagen, Build. Environ. 143, 120 (2018)

39. S.A. Nada, H.F. Elattar, A. Fouda, Energy Convers. Manag. 96, 208 (2015)

40. X. Zhou, L. Xu, J. Zhang, B. Niu, M. Luo, G. Zhou, X. Zhang, Energy Build. 211, 109795 (2020)

41. K. Katić, R. Li, W. Zeiler, Appl. Ergon. 85, 103078 (2020)

42. Z. Wang, J. Wang, Y. He, Y. Liu, B. Lin, T. Hong, J. Build. Eng. 29, 101120 (2020)

43. T.S. Larsen, L. Rohde, K.T. Jønsson, B. Rasmussen, R.L. Jensen, H.N. Knudsen, T. Witterseh, G. Bekö, Build. Environ. 172, 106707 (2020)

44. S. Carlucci, M.D. Simone, S.K. Firth, M.B. Kjærgaard, R. Markovic, M.S. Rahaman, M.K. Annaqeeb, S. Biandrate, A. Das, J.W. Dziedzic, G. Fajilla, M. Favero, M. Ferrando, J. Hahn, M. Han, Y. Peng, F. Salim, A. Schlüter, C. Treeck, Build. Environ. 174, 106768 (2020)

45. L. Pérez-Lombard, J. Ortiz, C. Pout, Energy Build. 40, 394 (2008)

46. X. Xu, W. Liu, Z. Lian, Energy Build. 220, 110086 (2020)

47. A.A. Chowdhury, M.G. Rasul, M.M.K. Khan, Appl. Energy 85, 449 (2008)

48. A. Gjerland, E. Søiland, F. Thuen, Build. Environ. 163, 106294 (2019)

49. L. Peeters, R. De Dear, J. Hensen, D. William, Appl. Energy 86, 772 (2009)

50. G.M. Stavrakakis, M.K. Koukou, M.G. Vrachopoulos, N.C. Markatos, Energy Build. 40, 1666 (2008)

51. K. Katic, R. Li, W. Zeiler, Appl. Ergon. 85, 103078 (2020)

52. N. Sakhri, Y. Menni, A.J. Chamkha, G. Lorenzini, H. Ameur, N. Kaid, M. Bensafi, J. Therm. Anal. Calorim. (2020). https://doi.org/10.1007/s10973-020-09867-6

53. F. Koçyigit, Int. J. Thermophys. 41, 41 (2020)

54. K.W. Mui, T.W. Tsang, L.T. Wong, J. Build. Eng. 29, 101117 (2019)

55. C. Foias, O. Manley, R. Rosa, R. Temam, Navier-Stokes Equations and Turbulence (Cambridge University Press, Cambridge, United Kingdom, 2001), pp. 1-6

56. H. Ameur, Energy 93, 1980 (2015)

57. H. Ameur, Chin. J. Chem. Eng. 24, 572 (2016)

58. H. Ameur, J. Hydrodyn. 28, 669 (2016)

59. H. Ameur, Chin. J. Chem. Eng. 24, 1647 (2016)

60. H. Ameur, ChemistrySelect 2, 11492 (2017)

61. H. Ameur, J. Food Eng. 233, 117 (2018)

62. H. Ameur, J. Appl. Fluid Mech. 11, 1739 (2018)

63. H. Ameur, Data Brief. 25, 104084 (2019)

64. H. Ameur, Food Bioprod. Proc. 117, 302 (2019)

65. H. Ameur, Period. Polytech. Mech. Eng. 64, 207 (2020) 
Publisher's Note Springer Nature remains neutral with regard to jurisdictional claims in published maps and institutional affiliations.

\section{Authors and Affiliations}

\section{Mohammed Bensafi ${ }^{1} \cdot$ Houari Ameur $^{2} \cdot$ Noureddine Kaid $^{1,2}$.} Siamak Hoseinzadeh ${ }^{3}$ (1) . Saim Memon ${ }^{4}$. Davide Astiaso Garcia ${ }^{3}$

1 Laboratory of Energetic in Arid Zones (ENERGARID), University Tahri Mohamed of Bechar, P.O. Box 417, 08000 Béchar, Algeria

2 Department of Technology, University Centre of Naama - Salhi Ahmed, P.O. Box 66, 45000 Naama, Algeria

3 Department of Planning, Design, and Technology of Architecture, Sapienza University of Rome, Rome, Italy

4 London Centre for Energy Engineering, School of Engineering, London South Bank University, 103 Borough Road, London SE1 0AA, UK 